\title{
Alkaline oxidative degradation of diphenylmethane structures - Activation energy and computational analysis of the reaction mechanism
}

\author{
Lubo Jurasek, Lívia Krištofová, Yujun Sun, and Dimitris S. Argyropoulos
}

\begin{abstract}
A diphenylmethane model compound (2,2'-methylenebis[6-methoxy-4-methylphenol]) and residual kraft lignin were treated with alkaline hydrogen peroxide. Kinetic data for the disappearance of the model and the diphenylmethane structures in the residual lignin was collected. The activation energies for the degradation were found to be similar $\left(54 \pm 11 \mathrm{~kJ} \mathrm{~mol}^{-1}\right.$ for the model and $58 \pm 5 \mathrm{~kJ} \mathrm{~mol}^{-1}$ for the residual lignin). A comparison of the activation energies with the data of a previous study on a biphenyl model compound (3,3'-dimethoxy-5,5'-dimethyl-[1,1'biphenyl]-2,2'-diol) showed a substantially higher activation energy for the degradation of the latter. Pathways for the degradation of 2,2'-methylenebis[6-methoxy-4-methylphenol] were proposed and the intermediates subjected to computational analysis using a semiempirical method (PM3). The results suggest that initially a common pathway exists, resulting in 2-[2-hydroxy-3-methoxy-5-methyl-phenylmethyl]-4-methyl-2,4-hexadienedioic acid. Then the pathway branches into three, resulting in three major degradation products. The main driving force of the reactions is the formation of radical sites after reaction with hydroxyl radicals and subsequent radical coupling with perhydroxyl radicals to form peroxides. All the reactions on the pathways are exothermic except for the transformations of peroxides into dioxetanes. The dioxetanes cleave exothermically resulting in ring cleavage and fragmentation. The computed data permitted for the rationalization as to why the diphenylmethane structures appear to be more labile than biphenyl structures under alkaline oxidative conditions.
\end{abstract}

Key words: activation energy, alkaline oxidative degradation, computational chemistry, lignin, reaction mechanism.

\begin{abstract}
Résumé : On a traité le 2,2'-méthylènebis[6-méthoxy-4-méthylphénol], un diphénylméthane modèle ainsi que de la lignine kraft résiduelle avec du peroxyde d'hydrogène en milieu alcalin. On a recueilli des données cinétiques relatives à la disparition du modèle et des structures diphénylméthane dans la lignine résiduelle. On a trouvé que les énergies d'activation pour la dégradation sont semblables $\left(54 \pm 11 \mathrm{~kJ} \mathrm{~mol}^{-1}\right.$ pour le modèle et $58 \pm 5 \mathrm{~kJ} \mathrm{~mol}^{-1}$ pour la lignine résiduelle). Une comparaison de ces énergies d'activation avec les données obtenues au cours d'une étude antérieure sur le 3,3'-diméthoxy-5,5'-diméthyl-[1,1'-biphényl]-2,2'-diol, un biphényle modèle, montre que l'énergie d'activation pour la dégradation de ce dernier est beaucoup plus élevée. Des voies réactionnelles sont proposées pour la dégradation du 2,2'-méthylènebis[6-méthoxy-4-méthylphénol] et on a soumis les intermédiaires à une analyse par calculs à l'aide d'une méthode semi-empirique (PM3). Les résultats suggèrent qu'initialement il existe une voie commune conduisant à la formation de l'acide 2-[2-hydroxy-3-méthoxy-5-méthyl-phénylméthyl]-4-méthylhexa-2,4-diènediö̈que. La réaction continuerait suivant trois voies qui conduiraient à trois produits différents. La force motrice principale des réactions est la formation de sites radicalaires après réaction avec des radicaux hydroxyles et le couplage radicalaire subséquent avec des radicaux perhydroxyles qui conduit à la formation de peroxydes. Toutes les réactions de chacune des voies réactionnelles sont exothermiques à l'exception des transformations des peroxydes en dioxétanes. Les dioxétanes se clivent d'une façon exothermique en provoquant des ouvertures de cycles et des fragmentations. Les données calculées permettent de rationaliser pourquoi, dans des conditions oxydantes en milieu alcalin, que les structures de type diphénylméthane semblent plus labiles que celles du type biphényle.
\end{abstract}

Mots clés : énergie d'activation, dégradation oxydante en milieu alcalin, chimie théorique, lignine, mécanisme réactionnel.

[Traduit par la Rédaction]

\section{Introduction}

Lignin is known to resist total degradation even under the severe conditions of kraft pulping, and only bleaching causes a substantial removal of residual kraft lignin from the fibre. Residual kraft lignin contains a significant amount of chromophoric structures such as biphenyl, diphenylmethane, $\alpha-5$, and stilbene units (1-4). The process of formation of condensed structures in lignin during various alkaline pulping processes has been recently investigated (4), using quan-

Received January 28, 2001. Published on the NRC Research Press Web site at http://canjchem.nrc.ca on September 21, 2001.

L. Jurasek, L. Krištofová, Y. Sun, and D.S. Argyropoulos. ${ }^{1}$ Paprican and Pulp and Paper Research Centre, Department of Chemistry, McGill University, 3420 University Street, Montréal, QC H3A 2A7, Canada.

${ }^{1}$ Corresponding author (telephone: (514) 398-6178; fax: (514) 398-8254; e-mail: dargyr@ po-box.mcgill.ca). 
Fig. 1. Comparison of activation energies for the alkaline oxidative degradation of diphenylmethane structures in residual kraft lignin and in the model compound MMMP.

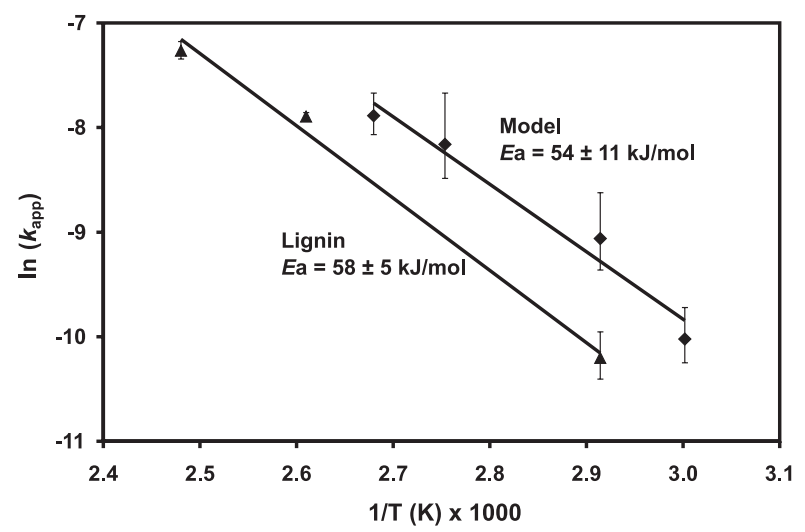

titative ${ }^{31} \mathrm{P}$ NMR spectroscopy. The cleavage of alkyl-aryl ether linkages during the kraft cook leads to the formation of new free phenolic hydroxyls and, consequently, their content in residual lignin as well as in soluble lignin increases during the cook (5). These cleavages lead to an enhancement of the content of condensed structures. Thus, it has been shown recently (4) that kraft pulping of milled wood lignin led to an increased content of stable biphenyl moieties, which eventually became an integral part of the residual kraft lignin structure. After Brunow and co-workers' (6) discovery of dibenzodioxocins in lignin, studies of their degradation under alkaline and kraft pulping conditions have shown conversion of dibenzodioxocins into phenolic alkylated biphenyl-type units within residual kraft lignin (7). Unlike biphenyl structures, which are present in native lignins and accumulate in residual lignin as other structures degrade, the diphenylmethane moieties are formed de novo by condensation of aromatic rings during soda or kraft pulping $(4,8)$, and analyses have shown that residual lignin in unbleached kraft pulp contains about $20 \%$ of diphenylmethane units (9).

Residual lignin can be degraded by a variety of bleaching reactions using either chlorine compounds or chlorine-free chemistry. Interest in minimizing the content of chlorinated compounds in mill effluents prompted, among other measures, the development of totally chlorine-free (TCF) bleaching based on oxygen chemistry. One of the variants of TCF bleaching is an alkaline hydrogen peroxide treatment. The chemistry of this process has been studied earlier and reactions with both anions and radicals have been considered (10-12). The aromatic rings appear stable to hydroperoxide anions (13) but react with hydroxyl radicals (10), which are believed to be the principal species responsible for the oxidative degradation of lignin (14). An alternative mechanism has been proposed (15) for 2,2'-methylenebis[6-methoxy-4methylphenol] (MMMP, protonated compound 4) degradation, which involves a nucleophilic attack by hydroperoxide anion. Hydrogen peroxide reacts with lignin in two ways: (i) peroxyl anions $\left(\mathrm{HOO}^{-}\right)$nucleophilically attack and eliminate lignin chromophores - these reactions are rapid and occur at low temperatures; (ii) hydroxyl radicals (HO'), superoxide radical anions $\left(\mathrm{OO}^{-}\right)$, or perhydroxyl radicals (HOO'), formed through the decomposition of hydrogen peroxide, oxidatively degrade phenolic structures into
Scheme 1. Degradation products of MMMP according to Sun et al. (18). The yields are in square brackets. These products may be formed by three different routes named butenedioate, furanacetate, and oxopentanoate pathways.
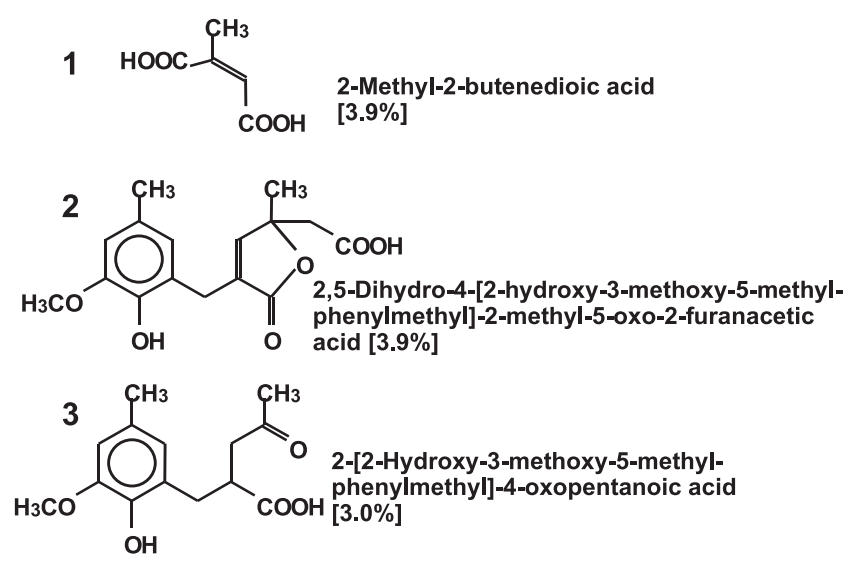

carboxylic acids. The radical reactions require higher temperature but lead to the scission of $\mathrm{C}-\mathrm{C}$ bonds, fragmentation, and dissolution of lignin, and thus, to its removal from fibre.

In our previous report (16) on the mechanism of alkaline oxidative degradation of a biphenyl-type model compound (3,3'-dimethoxy-5,5'-dimethyl-[1,1'-biphenyl]-2,2'-diol), we determined the activation energies for the degradation process and proposed various pathways. In the present effort, we focus on an analogous diphenylmethane model compound (MMMP) and on diphenylmethane structures in residual kraft lignin.

\section{Results and discussion}

\section{Activation energy}

The activation energy for the degradation of MMMP was determined to be $54 \pm 11 \mathrm{~kJ} \mathrm{~mol}^{-1}$, while that for the degradation of diphenylmethane structures in residual kraft lignin was $58 \pm 5 \mathrm{~kJ} \mathrm{~mol}^{-1}$ (Fig. 1). The finding that the activation energies are not significantly different suggests that the reaction mechanisms of the degradation may be similar and that MMMP might mimic the behaviour of diphenylmethane structures in lignin. A comparison with our previous study (16) on the activation energy $\left(117 \mathrm{~kJ} \mathrm{~mol}^{-1}\right)$ for the oxidative degradation of a biphenyl model compound (2,2'-dihydroxy3,3'-dimethoxy-5,5'-dimethyl-[1,1'-biphenyl]-2,2-diol) shows a substantial difference. Thus, we are finding, in agreement with a previous report (17), that biphenyl structures are more stable in an alkaline oxidative environment and a higher temperature is needed to degrade them effectively. While the activation energies of MMMP and diphenylmethane moieties in lignin are very similar, the apparent rate constants $\left(k_{\text {app }}\right.$ in Fig. 1) are approximately three times lower for lignin than for MMMP.

\section{Proposed mechanism of the oxidative degradation of diphenylmethane structures}

The products of degradation of 2,2'-methylenebis[6methoxy-4-methylphenol] (MMMP) under conditions similar to those used in this work were analyzed previously (18) and the main compounds were identified as shown in 
Scheme 2. First part of the common pathway starting with the anion $\mathbf{4}$ of the model compound (MMMP) leading (via radical mechanisms) to peroxide 10. Heats of formation of the compounds are given in brackets in $\mathrm{kJ} \mathrm{mol}^{-1}$. All reactants were taken into account and computed heats of reactions are shown next to the arrows. Partial charges (underlined) and electron spin densities (in italics) are indicated on some atoms.

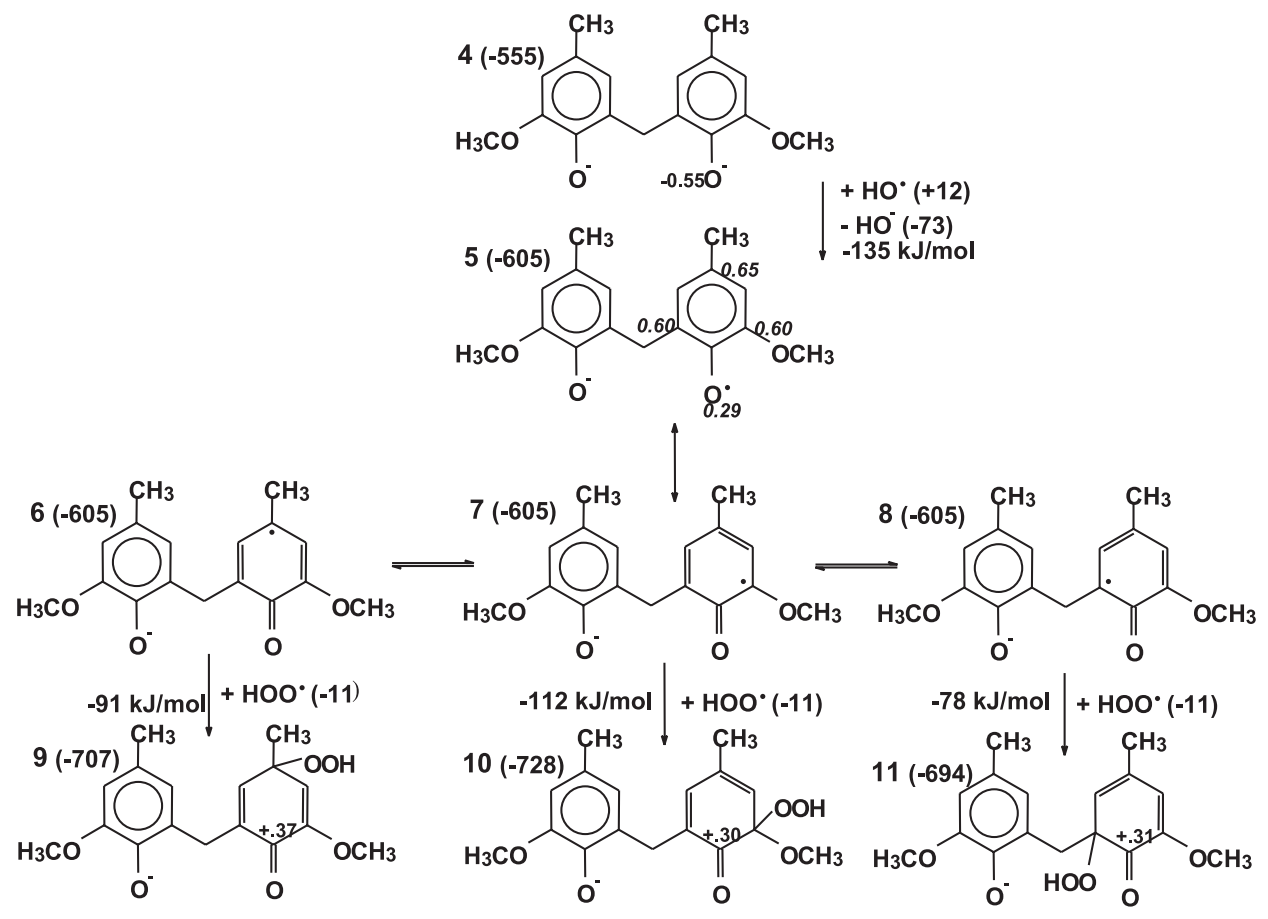

Scheme 1. The abundance of the three products was approximately equal ( 3 to $4 \%$ ), and none are predominant. It should be noted that the yields reported by Sun et al. (18) and quoted here are based on the starting compound. However, the reaction mixture in which the products were identified still contained $53.3 \%$ of unreacted material. Thus, the respective yield figures for compounds $\mathbf{1}-\mathbf{3}$ should be quoted as $8.4,8.4$, and $6.4 \%$, respectively. The reaction mixture also contained a number of minor products accounting altogether for $36.6 \%$ of the converted material. To these products we should also add oxalic acid, which is accounted for by one of our pathways and was subsequently found upon reinspection of the lab records in a $4 \%$ yield. Therefore, approximately $40 \%$ of the converted material was accounted for as products.

In this work we have made an attempt to devise the simplest reaction pathways explaining the formation of the products determined previously (18). Our efforts were guided by the results of the computations as well as by previously published pathways for oxidative degradation of similar compounds (11-14). The results of this effort suggest the existence of a common initial pathway leading to the formation of an intermediate dicarboxylic compound (2[2-hydroxy-3-methoxy-5-methyl-phenylmethyl]-4-methyl2,4-hexadienedioate) (compound 14). From this intermediate, the pathway branches into three, each of which leads to formation of one of the three main degradation products. We will now describe the proposed pathways in some detail.

\section{The common initial pathway}

The oxidative degradation of MMMP is initiated by an electrophilic attack by hydroxyl radicals (Scheme 2). The phenolate groups of the MMMP dianion (4) have been computed as the most electronegative sites and therefore, likely points of an attack by electrophilic hydroxyl radicals. The charges on the phenolate groups $(-0.55)$ are more negative than the corresponding groups on an analogous biphenyl model compound investigated previously (17) (charge -0.53 ), which could contribute to the higher reactivity of MMMP as compared to an analogous biphenyl compound.

The resulting phenoxy radical 5 (Scheme 2), shows high electron spin densities $(0.65,0.60$, and 0.60$)$ in three positions on the ring suggesting the three resonant structures $\mathbf{6}$, $\mathbf{7}$, and $\mathbf{8}$, respectively. Any one of these three radical sites could couple with the perhydroxyl radical present in the reaction mixture but one of the resulting peroxides (10) is most favorable thermodynamically (heat of formation -728 $\mathrm{kJ} \mathrm{mol}{ }^{-1}$, compared with -707 and $-694 \mathrm{~kJ} \mathrm{~mol}^{-1}$ of the other two peroxides, 9 and 11). Therefore, it is reasonable to assume that peroxide $\mathbf{1 0}$ is the predominant intermediate. The computed heats of formation of all reactants leading to 10 indicate exothermic reactions, which supports the proposed pathway. We have also attempted to compute the products derived from the other two peroxides (9 and 11) but found no feasible pathways leading to the experimentally identified products.

In analogy with our previous study (16), we assume that perhydroxyl radical rather than superoxide radical anion is the reactive species involved in the radical coupling reactions. Couplings with superoxide radical anions gave us products with unreasonably high values of heats of formation. However, our computations were done in vacuo and we plan to address this question again in future using solvated intermediates. 
Scheme 3. Second part of the common pathway starting with peroxide $\mathbf{1 0}$ and leading to a dicarboxylic intermediate (14). The intermediate is a point from which three pathways branch off and lead to the anions 15-17 of the main products (1-3) described by Sun et al. (18). See Scheme 2 for the explanation of symbols.
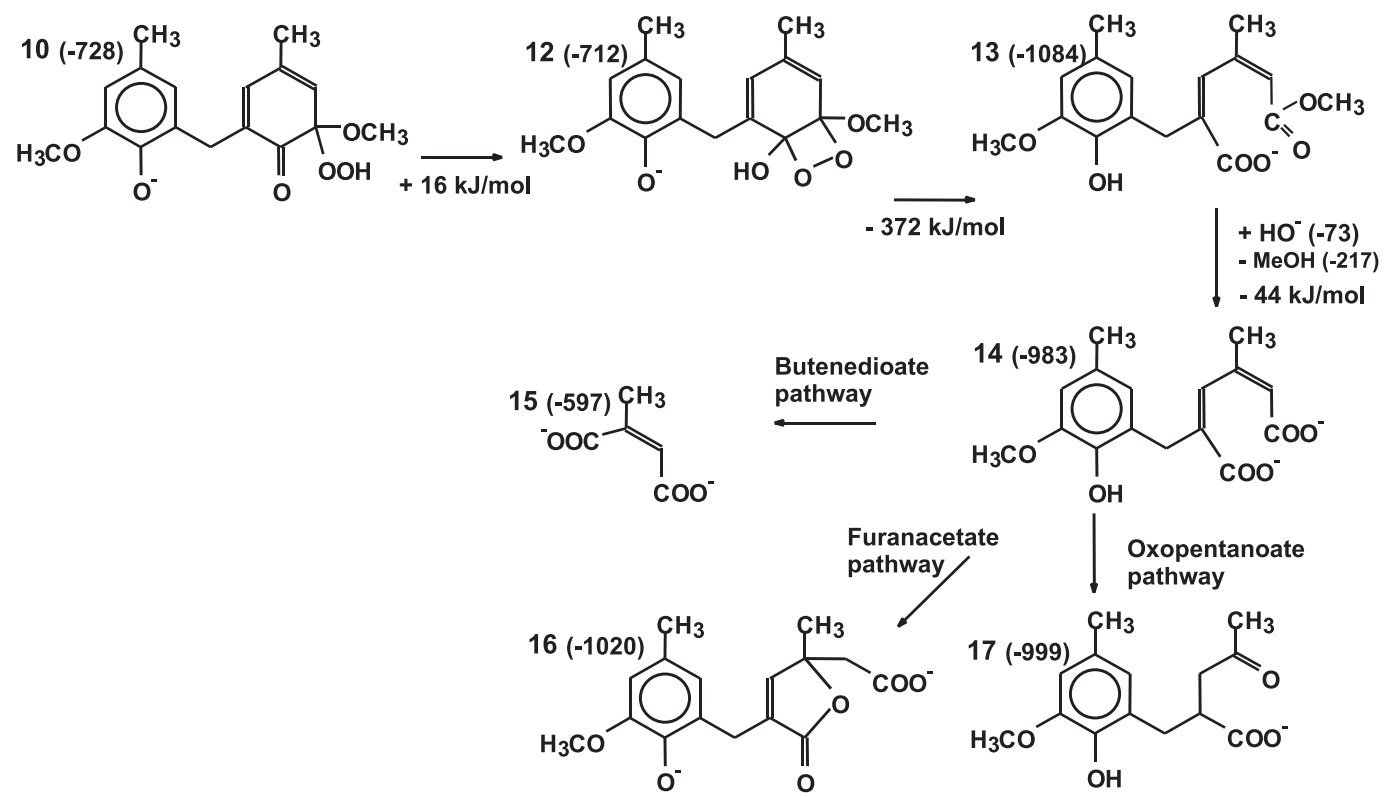

Scheme 4. The butenedioate branch pathway starts with the dicarboxylic intermediate $\mathbf{1 4}$ and proceeds via radical reactions toward a dianion 15 of the degradation product 1, determined by Sun et al. (18). See Scheme 2 for the explanation of symbols.

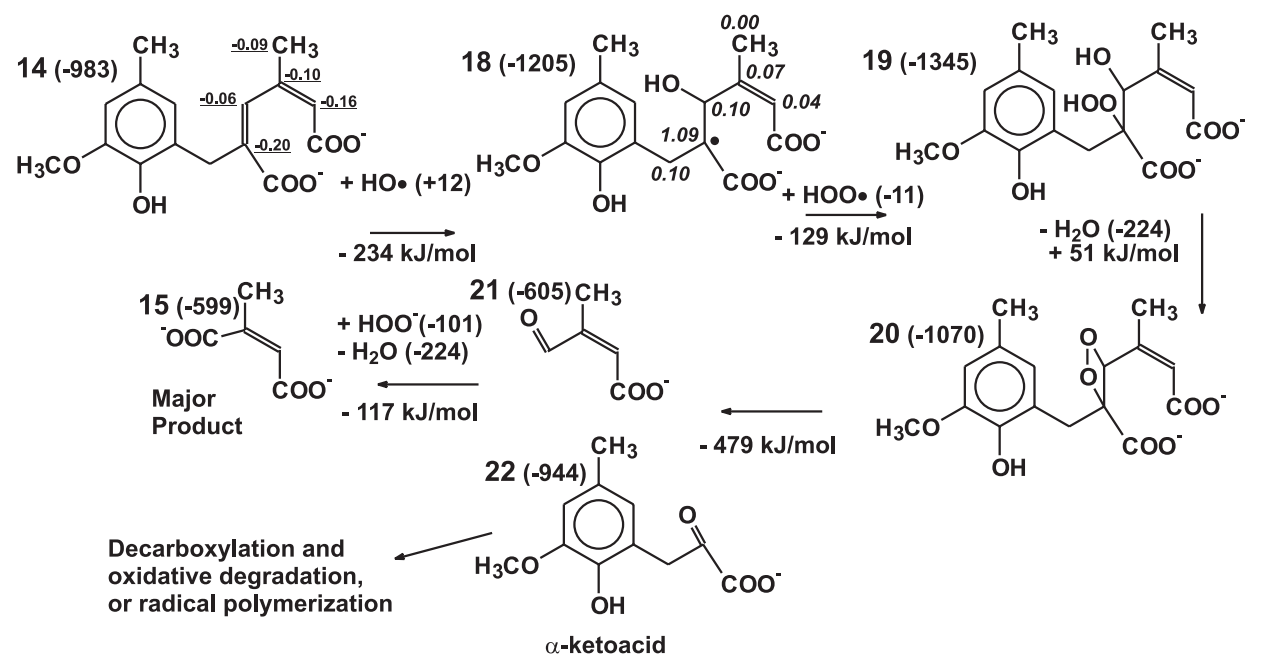

The favorable peroxide intermediate $\mathbf{1 0}$ is predicted to undergo further degradation as shown in Scheme 3. The peroxide transforms into a dioxetane (12) by an endothermic reaction calculated to consume $16 \mathrm{~kJ} \mathrm{~mol}^{-1}$. The required heat of reaction is similar to that reported for an analogous reaction of the biphenyl model compound studied previously $\left(15 \mathrm{~kJ} \mathrm{~mol}^{-1}\right)(16)$. The possible meaning of the endothermic reactions for considering the thermodynamic barriers will be discussed later in this section.

Following the formation of the dioxetane 12, we predict that a highly exothermic $\mathrm{C}-\mathrm{C}$ scission (formation of 13) followed by demethylation yields a dicarboxylic intermediate (2[2-hydroxy-3-methoxy-5-methylphenylmethyl]-4-methyl-2,4hexadienedioate) 14. The intermediate provides a branching point for the forthcoming three pathways named butenedioate, furanacetate, and oxopentanoate pathways, respectively, according to the anions $\mathbf{1 5}-\mathbf{1 7}$, of the experimentally proven (18) final products $\mathbf{1}-\mathbf{3}$, respectively. We will now discuss the subsequent concurrent pathways.

\section{The butenedioate pathway}

The pathway is outlined in Scheme 4. The degradation of the intermediate $\mathbf{1 4}$ is believed to be initiated by another attack by a hydroxyl radical. Such attack usually occurs at a strongly electronegative site but to substantiate the degradation of the aliphatic chain leading to the formation of one of the final products (15), we must assume that the attack by hydroxy radical (and the ensuing radical addition) occurs at a carbon atom with a small negative charge (computed as 
Scheme 5. Computations of ionization states of two analogous degradation products (23 and $\mathbf{2 5}$ ) suggest preferential ionization of the phenolic hydroxyl of the hypothetical product 23 . See Scheme 2 for the explanation of symbols.

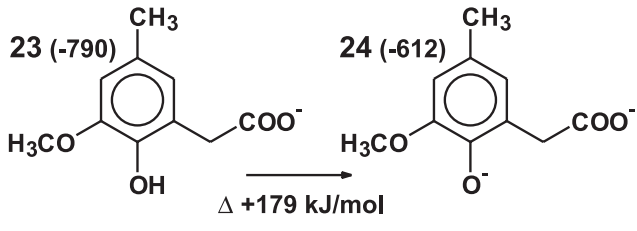

Diphenylmethane model degradation product (hypothetical)

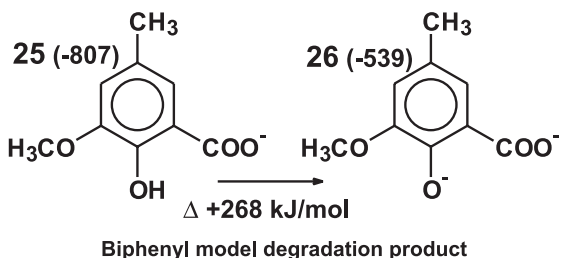

-0.06). The radical addition results in a radical (18) with high spin density (1.09) at the site of coupling reaction with a perhydroxyl radical. The coupling results in the formation of a peroxide (19). Both the radical addition and coupling reactions are exothermic according to the computations. However, for the peroxide to form the dioxetane $(\mathbf{2 0})$, the computations suggest that $51 \mathrm{~kJ} \mathrm{~mol}^{-1}$ heat has to be supplied.

The dioxetane $\mathbf{2 0}$ then cleaves exothermically to yield a product (21), which upon exothermic oxidation with hydroperoxyl anion, leads to the formation of $\mathbf{1 5}$ - an anion of one of the major products (1), determined experimentally (18). The degradation of $\mathbf{2 0}$ also leads to the formation of an $\alpha$-keto acid (22). An analogous reaction with a biphenyl model compound computed previously (16), led (after decarboxylation and oxidation of an analogous $\alpha$-keto acid) to the formation of 2-hydroxy-3-methoxy-5-methylbenzoic acid, the main product of the biphenyl model compound degradation. However, no analogous aromatic acid was found among the degradation products of MMMP. Scheme 5 illustrates an attempt to explain this apparent discrepancy. Compound 22 (Scheme 4) may yield the hypothetical intermediate (23) (Scheme 6), after decarboxylation and oxidation analogous to that proposed previously (16) for the formation of of 2-hydroxy-3-methoxy-5-methylbenzoic acid (its phenolate anion (25) is shown in Scheme 5). However, computations of heats of formation shown in Scheme 5 suggest that the hypothetical product (23), compared to $\mathbf{2 5}$, is more likely to yield a phenolate anion (24), which would then become subject of an attack by hydroxyl radicals and could undergo further degradation or polymerization reactions. This could explain why the hypothetical intermediate (23) is not found among the MMMP degradation products (18). Alternatively, Scheme 5 suggests that the analogous biphenyl model degradation product (25) produces a phenolate much less readily. It is therefore unlikely to undergo further degradation reactions and is present among the biphenyl model degradation products (18). It should be noted that in the reactions shown in Scheme 5, the hydrogen ions have been omitted and therefore, the differences in
Scheme 6. Furanacetate branch pathway starting with the common dicarboxylic intermediate $\mathbf{1 4}$ and results in an anion (16) of a major degradation product (2), determined by Sun et al. (18). See Scheme 2 for the explanation of symbols.<smiles>COc1cc(C)cc(CC(=CC(=O)[O-])C(=O)[O-])c1O</smiles>

the heats of formation do not indicate the heats of ionization.

\section{The furanacetate pathway}

This branch pathway (Scheme 6) consists of exothermic lactonization of the dicarboxylic intermediate (14), yielding an anion (16) of the furanacetic acid product $\mathbf{2}$ (Scheme 1).

\section{The oxopentanoate pathway}

This pathway is the third of the branching pathways. Its course is outlined in Scheme 7. As the previous two it also starts from the dicarboxylic intermediate 14. Computational investigation of several variants of this pathway led to this scheme judged to be thermodynamically most favourable. We presume that an exothermic reaction with a hydroxyl radical leads to hydrogen abstraction from the intermediate 14, resulting in a benzylic radical species (27), with high spin density $(0.91)$ at the site of coupling reaction with a perhydroxyl radical. This exothermic reaction yields a peroxide (28). Transformation of $\mathbf{2 8}$ into a dioxetane structure (29) is predicted to be an endothermic reaction $\left(+56 \mathrm{~kJ} \mathrm{~mol}^{-1}\right)$. The dioxetane 29 then undergoes an exothermic $\mathrm{C}-\mathrm{C}$ scission and yields an anion (17) of a major degradation product (3), identified previously (18). A byproduct of the scission is predicted to be oxalate $\mathbf{3 0}$, originally not noticed (18) due to a very low gas chromatography response factor. A review of the analytical data (unpublished) revealed the presence of about $2 \%$ of oxalic acid among the reaction products, in agreement with this prediction.

\section{Alternative radical reactions}

In addition to the pathways described above, we explored other reactions as alternatives. Thus, hydrogen abstraction from the diphenylmethyl carbon of MMMP rather than formation of a phenoxy radical was considered as a likely reaction leading to the formation of a stable diphenylmethane radical. However, we could not derive the experimental products (Scheme 1) from this intermediate. Possible alternatives to hydrogen abstraction reactions in Scheme 7 could be hydroxyl radical additions to unsaturated structures. We have computed two such scenarios and were able to arrive at the determined products but the computed reactions appeared thermodynamically less favourable (the barriers were +84 and $\left.+115 \mathrm{~kJ} \mathrm{~mol}^{-1}\right)$. It is interesting to note that Sun et al. (18) reported a low yield $(0.5 \%)$ of a 1 -hydroxylated derivative of compound $\mathbf{2}$. This derivative is probably a product of a hydroxyl radical addition reaction. We also computed an alternative to Scheme 4 , based on hydrogen abstraction from an unsaturated carbon. Although the alterna- 
Scheme 7. The oxopentanoate branch pathway starting with the common intermediate $\mathbf{1 4}$ and leading, via radical reactions, to an anion (17) of the major product 3, determined by Sun et al. (18). See Scheme 2 for the explanation of symbols.

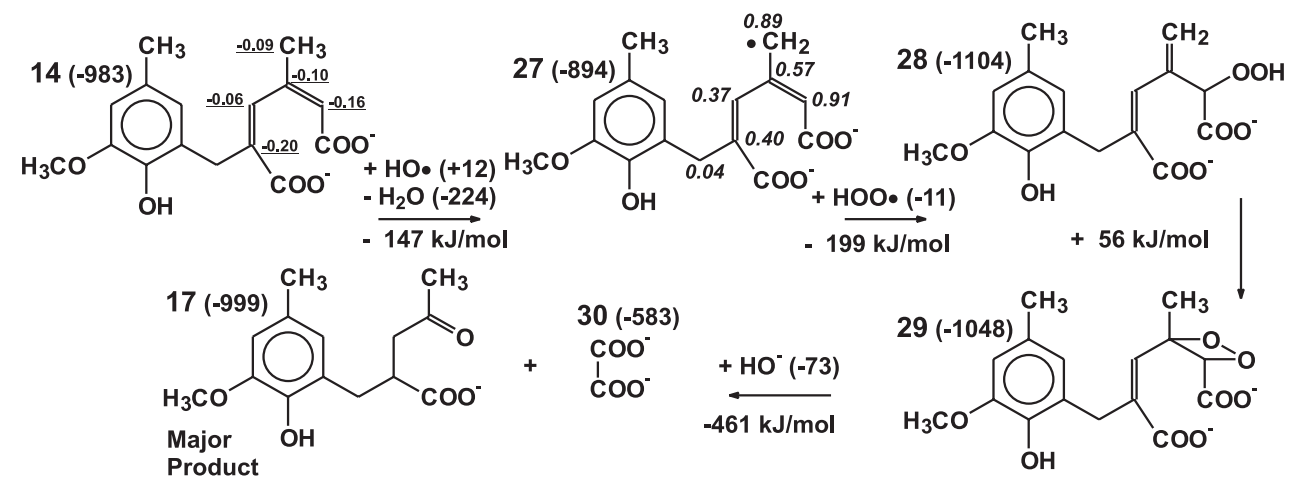

tive yielded a barrier marginally lower $(+50$ instead of +51 $\mathrm{kJ} \mathrm{mol}^{-1}$ ) we did not consider it likely.

There is little doubt that, in addition to reactions proposed in Schemes 2-7, various alternative reactions take place during the oxidative degradation of the diphenylmethane structures. However, the outcome of these reactions may have been either a condensation or conversion of the substrate to carbonate, explaining why the overall yields of the reaction products were not quantitative (see Scheme 1 and a discussion of the yields).

\section{Barriers on the reaction pathways}

In our previous investigation (16) of a biphenyl-type model compound, we concluded from our computations that the only endothermic steps on the degradation pathway are transformation reactions of peroxides into corresponding dioxetanes. It should also be noted that all such transformations were computed as endothermic. It is significant that the same rule can be extended to all pathways presented in this work on MMMP. Consideration of reaction barriers in this case is somewhat complicated by the branching of the pathway. However, the common initial pathway (Schemes 2 and 3 ) has one endothermic step $\left(+16 \mathrm{~kJ} \mathrm{~mol}^{-1}\right.$, Scheme 3$)$ after which there is no barrier to the end of the furanacetate branch (Scheme 6). Therefore, this barrier could be the one controlling the disappearance of MMMP. In comparison, the disappearance of the biphenyl compound encounters a much greater barrier further down the pathway (+94 $\mathrm{kJ} \mathrm{mol}^{-1}$ ) (16). The activation energy for the disappearance of MMMP is also lower $\left(54 \pm 11 \mathrm{~kJ} \mathrm{~mol}^{-1}\right)$ than the previously determined activation energy $\left(117 \mathrm{~kJ} \mathrm{~mol}^{-1}\right)$ for the biphenyl model (16).

Significant endothermic steps have been computed on the other two branch pathways, butenedioate and oxopentanoate (+51 and +56 kJ mol ${ }^{-1}$, respectively; see Schemes 4 and 7). These values are similar to the experimentally determined activation energy for the disappearance of the model compound MMMP. It is tempting to speculate that the activation energy reflects these barriers. Thus it seems that not only the disappearance of MMMP but also the formation of the degradation products encounters lower energy barriers than those observed for the degradation pathway of the analogous biphenyl model (16).

\section{Experimental}

\section{Materials}

MMMP used in this work was synthesized according to Kratzl and Virhopper (19). 3,4-Dimethoxyphenol (97\%) was used for GC-FID quantification; 2-chloro-4,4,5,5-tetramethyl1,3,2-dioxaphospholane (95\%) was used as a phosphitylation reagent; magnesium sulphate $(99.99 \%)$, sodium hydroxide (99.99\%), and potassium iodide $(99.9 \%)$ were purchased from Aldrich. Distilled water used in this study was treated with a NANO pure Analytical Deionization System (Barnstead).

\section{Activation energy}

The degradation of 2,2'-methylenebis[6-methoxy-4-methylphenol] (MMMP; an anion of this compound (4) is shown in Scheme 2) was carried out in dilute alkali with hydrogen peroxide at four different temperatures $(60,70$, 90, and $100^{\circ} \mathrm{C}$ ) for various intervals $(5-60 \mathrm{~min})$. The $\mathrm{pH}$ of the starting reaction mixture was 12.4 . Under the most extreme conditions $\left(100^{\circ} \mathrm{C}\right.$ for $\left.45 \mathrm{~min}\right)$, the $\mathrm{pH}$ dropped to about 10.2 after the reaction. The molar excess of hydrogen peroxide over MMMP was high enough to maintain residual hydrogen peroxide at $>15 \%$ of the original amount under all conditions of the kinetic study. The amount of unreacted MMMP was identified using GC-FID analyses; the lowest recorded yield was $28 \%$ of the original amount.

A similar set of reactions with residual kraft lignin was carried out at 70,110 , and $130^{\circ} \mathrm{C}$ for $15-90 \mathrm{~min}$. Phenolic hydroxyl groups in the diphenylmetane structures were assayed using quantitative ${ }^{31} \mathrm{P}$ NMR spectroscopy. These structures show a ${ }^{31} \mathrm{P}$ chemical shift signal in the interval 142.7-144.0 ppm. The original amount of these groups was $0.243 \mathrm{mmol} \mathrm{g}^{-1}$ and dropped to about $10 \%$ of this at the most extreme treatment conditions $\left(90 \mathrm{~min}\right.$ at $\left.110^{\circ} \mathrm{C}\right)$.

From the reaction rates measured at various conditions, we calculated apparent reaction constants $\left(k_{\text {app }}\right)$ and determined their errors from the errors of the corresponding plots. The activation energies for the oxidative degradation of: (i) MMMP; and (ii) diphenylmethane structures in residual kraft lignin, were calculated from the kinetic data using the Arrhenius equation (20). The errors of the $E_{\mathrm{a}}$ estimates were calculated using averages of the errors of the $\ln \left(k_{\text {app }}\right)$ data. 
Treatment of 2,2'-methylenebis[6-methoxy-4-methylphenol]

MMMP was oxidized with hydrogen peroxide as a function of time and temperature using a $40-\mathrm{mL}$ glass-lined steel bomb reactor. The molar ratio of MMMP to hydrogen peroxide and sodium hydroxide was 1:6:4, respectively. To approximately $100 \mathrm{mg}$ of MMMP in the glass liner we added $20 \mathrm{~mL}$ of deionized water, $1.23 \mathrm{mg}$ of magnesium sulphate in solution, and $58.4 \mathrm{mg}$ of sodium hydroxide in solution. The mixture was heated and stirred for $5 \mathrm{~min}$ to solubilize the ingredients. After cooling, $190 \mu \mathrm{l}$ of $30 \%$ aqueous hydrogen peroxide was added and the whole transferred into a glass liner and covered with a glass lid. The reactor was sealed and placed in a preheated oil bath, and kept there for the specified time. At the end of the reaction, the reactor was rapidly cooled and $2 \mathrm{~mL}$ of the reaction mixture was withdrawn for measurement of the residual hydrogen peroxide. The $\mathrm{pH}$ of the solution after reaction (9.5-11.8) was adjusted to about 2 with $1 \mathrm{~N}$ hydrochloric acid. The mixture was then lyophilized and the solids extracted three times with approximately $5 \mathrm{~mL}$ of ethyl acetate. Before weighing the solute, the extract was placed into a preweighed vial, allowed to dry at room temperature, and then desiccated in vacuo for 2 days.

\section{Treatment of residual kraft lignin}

The procedure was similar to that used for the model compound. Residual kraft lignin from black spruce kraft pulp (50 mg, i.e., $0.273 \mathrm{mmol}$ of C9 units), free of metal, was suspended in $1 \mathrm{~mL}$ of deionized water and $1 \mathrm{~mL}$ of $1 \mathrm{~N}$ sodium hydroxide was added. The $\mathrm{pH}$ of the suspension was 13.4. Hydrogen peroxide $(65 \mu \mathrm{l}, 30 \%$ in water) was then added at the molar ratio of lignin C9 units to hydrogen peroxide, equal to 1:2.3. At the end of the reaction period, the mixture was acidified to $\mathrm{pH} 2$. The precipitated degraded lignin was then lyophilized and brought to constant weight.

\section{Gas chromatography with flame ionization detection (GC-FID)}

The analyses were carried out on a Hewlett-Packard 5890A gas chromatograph equipped with a DB-5 capillary column. The injection port temperature was $250^{\circ} \mathrm{C}$ and the oven temperature was raised from $70^{\circ} \mathrm{C}$ to $250^{\circ} \mathrm{C}$ with a gradient of $15^{\circ} \mathrm{C} \mathrm{min}$. One $\mathrm{mL}$ of pyridine was added to the dry product and the vial was immediately closed and shaken until all dissolved. Fifty $\mu l$ were transferred to a new vial and $0.3 \mathrm{~mL}$ of pyridine and $100 \mu \mathrm{L}$ of internal standard solution was added. The internal standard was 3,4dimethoxyphenol $(1.004 \mathrm{mg}$ in $100 \mu \mathrm{L}) . N, O$-Bis(trimethylsilyl)acetamide was added as a silylation reagent. The GC response factor relative to the internal standard was determined as follows: accurately measured amounts of the internal standard and diphenylmethane were mixed well in pyridine. Then the sample was silylated and the resulting solution injected. The integrated areas from GC were compared to determine the response factor.

\section{Quantitative ${ }^{31} \mathbf{P}$ NMR analysis}

Lignin samples were analyzed for the content of diphenylmethane structures using a previously published method (21).

\section{Computational methods}

All compounds listed in the various schemes have been subjected to computational analysis of the geometryoptimized structures. The optimization was done using the third parametrization semiempirical method (PM3) $(22,23)$ after subjecting the structures to simulated annealing and preliminary optimization with a molecular mechanics method (MM+) derived from the method of Allinger (24). All computational methods were used as implemented by HyperChem Professional, Version 5.11 (HyperCube, Inc.). The details of the computational protocol were the same as described previously (16). The values of heats of formation, charges on individual atoms, and electron spin densities $(\alpha-\beta$ atomic orbital electron populations) were computed on the optimized structures.

\section{Conclusions}

The activation energy for the alkaline oxidative degradation of the diphenylmethane model compound $\left(2,2^{\prime}\right.$ methylenebis[6-methoxy-4-methylphenol]) (MMMP) and diphenylmethane structures in residual lignin is similar (54 \pm 11 and $58 \pm 5 \mathrm{~kJ} \mathrm{~mol}^{-1}$, respectively), supporting the relevance of MMMP to represent diphenylmethane moieties of kraft lignins.

The critical steps in the degradation sequence may be the aromatic ring cleavage and the scission of the newly formed aliphatic side chain.

Both aromatic and aliphatic scission mechanisms may be similar and might consist of the following steps: (i) formation of radical sites by reactions with hydroxyl radicals; (ii) radical coupling reactions of the radical sites with perhydroxyl radicals, resulting in formation of peroxides; (iii) transformation of peroxides into dioxetanes; (iv) scission of the dioxetane structures.

MMMP is more easily degraded (as reported by Johansson and Ljunggren (17)) than the corresponding biphenyl model for these main reasons: $(i)$ the activation energy for the disappearance of MMMP is lower; (ii) the critical endothermic reactions on the MMMP degradation pathway require less energy; (iii) the initial electrophilic attack by a hydroxyl radical is facilitated by the more electronegative phenolic hydroxyl oxygen; (iv) the course of the degradation of the diphenylmethane structures branches into at least three pathways thus providing multiple ways for the structure to degrade; $(v)$ carboxylic acid group formation during the degradation of the diphenylmethane moieties provides less protection for the residual aromatic structures due to the greater distance from the phenolic hydroxyl.

The above conclusions from the model compounds can probably be extended to the biphenyl and diphenylmethane structures in lignin.

\section{Acknowledgements}

We wish to thank Dr. Peter McGarry (Paprican) for valuable comments and suggestions. Professor Leif Eriksson (Department of Quantum Chemistry, Uppsala University, Sweden) kindly provided us with advice on computation methods. 


\section{References}

1. Z.-H. Jiang and D.S. Argyropoulos. J. Pulp Paper Sci. 25, 25 (1999).

2. T. Eriksson and J. Gierer. J. Wood Chem. Technol. 5, 53 (1985).

3. A. Granata and D.S. Argyropoulos. J. Agric. Food Chem. 43, 1538 (1995).

4. B. Ahvazi, G. Pageau, and D.S Argyropoulos. Can. J. Chem. 76, 506 (1998).

5. K. Toven. Int. Symp. Wood Pulping Chem. 10th. 1999. Vol. II, 340 (1999).

6. P. Karhunen, P. Rummakko, J. Sipila, J. Brunow, and I. Kilpelalnen. Tetrahedron Lett. 36, 169 (1995).

7. P. Karhunen, J. Mikkola, A. Pajunen, and G. Brunow. Nord. Pulp Pap. Res. J. 14, 123 (1999).

8. D.S. Argyropoulos and S.B. Menachem. Lignin. In Advances in biochemical engineering/biotechnology. Vol. 57. Edited by K.E. Erickson. Springer-Verlag, Berlin, Heidelberg. 1997. pp. 127-158.

9. Y.Z. Lai, M. Funaoka, and H.T. Chen. Int. Symp. Wood Pulping Chem. 7th. 1993. 308 (1993).

10. J. Gierer and F. Imsgard. Svensk. Papperstidn. 80, 510 (1977).

11. C.W. Bailey and C.W Dence. Tappi J. 52, 491 (1969).
12. G. Gellerstedt, K. Gustafsson, and E.-L. Lindfors Nord. Pulp Paper Res. J. 1, 14 (1986).

13. J. Gierer. Holzforschung, 51, 34 (1997).

14. J. Gierer, E. Yang, and T. Reitberger. Holzforschung, 46, 495 (1992).

15. H. Xu and Y.Z. Lai. J. Wood Chem. Technol. 17, 223 (1997).

16. L. Jurasek, Y. Sun, and D.S. Argyropoulos. A detailed study of the alkaline oxidative degradation of a residual kraft lignin model compound. In Fundamentals and catalysis of oxidative delignification processes. Edited by D.S. Argyropoulos. ACS Books Series 785. American Chemical Society, Washington, D.C. 2001. pp. 130-148.

17. E. Johansson and S. Ljunggren. J. Wood Chem. Technol. 14, 507 (1994).

18. Y. Sun, M. Fenster, A. Yu, R.M. Berry, and D.S. Argyropoulos. Can. J. Chem. 77, 667 (1999).

19. K. Kratzl and F.W. Virhopper. Monatsh. Chem. 102, 425 (1971).

20. S.R. Radel and M.H. Navidi. Chemistry. 2nd ed. West Publishing Company, St. Paul, Minnesota. 1994. pp. 663-668.

21. B.C. Ahvazi and D.S. Argyropoulos. Nord. Pulp Paper Res. J. 12, 282 (1997).

22. J.J.P. Stewart. J. Comput. Chem. 10, 209 (1989a).

23. J.J.P. Stewart. J. Comput. Chem. 10, 221 (1989b).

24. N.L. Allinger. J. Am. Chem. Soc. 99, 8127 (1977). 
Copyright $\odot 2003$ EBSCO Publishing 